\title{
The Laws of Distribution of the Values of Turbulent Thermo-physical Characteristics in the Volume of the Flows of Heat Carriers Taking into Account the Surface Forces
}

\author{
Yuriy Bilonoga $^{1,2 *}$, Oksana Maksysko $^{1}$ \\ ${ }^{1}$ Faculty of Food Technologies and Biotechnology, Stepan Gzytsky Natoinal University of Veterinary Medicine and \\ Biotechnologies Lviv, 50 Pekarska, Lviv 79010, Ukraine \\ ${ }^{2}$ Ukraine and Lviv Institute of Economy and Tourism Lviv, Lviv 79010, Ukraine
}

Corresponding Author Email: yuriy_bilonoha@ukr.net

https://doi.org/10.18280/ijht.370101

Received: 3 June 2018

Accepted: 23 December 2018

\section{Keywords:}

turbulent number Blturb., turbulent and transitional viscosites, turbulent and transitional conductivites, coefficient of surface tension, shell-and-tube heat exchanger

\section{ABSTRACT}

The distribution of resistances values of individual thermal zones of coolants flows is analyzed for the example of milk and water in a shell-and-tube heat exchanger, which was calculated and selected by us in the work [11]. It is shown that thermal resistance of turbulent zones of coolants flows is about $37 \%$ of the total thermal resistance of the heat exchange system in this heat exchanger. The specific thermals resistivity the laminar boundary layer (LBL) zones are much larger, but their total thermal resistance is about $1.5 \%$ because of the very small average thickness of these zones. In this case, the method of analyzing the basic dimensions of physical quantities was used. At the same time, we deduced a new dimensionless number $B l_{\text {turb. }}$, which shows the ratio of turbulent viscosities or thermal conductivities to the transitional viscosities or thermal conductivities of the individual coolants zones. Formulas for the calculation of turbulent viscosities and thermal conductivities in coolants of are derived and the law of their distribution in the volume of coolant flows in the pipes and the annular space of the shell-andtube heat exchanger is established. It is shown that this law is an analog of the bell-shaped law of the distribution of Reichardt H. and Ludwig H., and the main difference is that the equation of this law derived by us contains the coefficients of surface tension and hydrophilicity of the wetting surfaces and also the values, reflecting the rates of thermal motion of the heat carriers molecules at a given temperature. A complete analysis of longitudinal sections of coolants flows is made using the example of milk and water in a shell-and-tube heat exchanger for their values of turbulent viscosities and thermal conductivities as well as the turbulent numbers $B l_{\text {turb. }}$ It is shown that the most energy-efficient liquid refrigerants can be selected using a turbulent number $B l_{\text {turb. }}$.

\section{INTRODUCTION}

1.1 Existing hypotheses on the distribution of values of thermo-physical characteristics in the volumes of the coolants flows

An important integral characteristic of the country and the enterprise is the indicator of their energy efficiency. This indicator depends on the correct choice of energy-efficient heat exchange equipment, since losses in the heat and energy sector are the most significant and affect not only the country's environmental balance but also its healthcare system.

The efficiency of the heat exchange equipment depends largely on the rational choice of liquid and gaseous media, where their heat transfer properties directly depend on the structure and optimal distribution of the thermal properties in the heat carriers flows.

Reichardt H. [1] deduced the dependence of the distribution of the temperature field in the volume of the liquid flow on the momentum distribution rate (1):

$$
\frac{T_{\min }}{T_{\max }}=\left(\frac{v_{\min }}{v_{\max }}\right)^{\frac{A_{\tau}}{A_{q}}}
$$

In the formula (1) for approximate technical calculations, the ratio of the coefficients of pulses $A_{\tau}$ and heat transfer $A_{q}$ in the middle part of the pipeline Schlichting H. recommends taking from 0.5 to 1.0 , about 0.7 [2].

Later Ludwieg H. [3] confirmed this dependence. They derived a characteristic bell-shaped law for the distribution of velocity and temperature pulses in the volume of the pipeline, which resembles the normal Gaussian distribution law. These results seem to us to be the most important, since Reichardt $\mathrm{H}$. and Ludwieg H. did not rely on any theory of turbulence, and made inferences only on the basis of their experimental data.

Later Rogatski G. [4] showed that the characteristic bellshaped form of this distribution is almost identical irrespective of the models of the theory of turbulence proposed by Prandtl L., Reynolds O., Taylor G., Karman Th. et al. This concept can be used for consistency and comparison of differently formulated turbulent flow models.

1.2 The distribution hypothesis with allowance for surface forces at the boundary of the wall and the coolant

Earlier, in the papers [5-6], we proposed a concept for considering the contacting of metallic surfaces with allowance for the surface energy and of the energy of the bond of the contacting metals. In the work [7] we outlined the basic 
principles of the development of a wear-resistant semi-liquid lubricant into which soft metal powders with low surface energy values were introduced. The metal powder was used as a soft damping layer and protected the main metal surfaces from rapid wear, and the base was a semi-liquid lubricant [7]. These issues are very important in considering the processes of thermal and fretting corrosion, in particular, anchor bolts and other heavily loaded fretting and friction assemblies [8].

In the work [9], we proposed the same concept as in the works [5-7], only for the surface of a metal and a moving fluid. This is the concept of the movement of a fluid near a solid metal wall (coolant flow - tube walls), taking into account surface tension forces, the values of which in an LBL are commensurate with pressure forces and significantly exceed gravity, friction and inertia. That is, the Euler numbers and the surface numbers calculated by us are much higher than the Reynolds and Froude numbers in LBL [19]. Based on this concept, we obtained formula (1) in our previous work for calculating the average thickness of LBL when a liquid heat carrier moves near a solid metal wall.

$\delta=\frac{\sqrt{\frac{\sigma \cos \theta d}{\Delta P}}}{K_{\text {turb }}}$

In the work [9], using the example of two model liquids (water and milk), we proposed a new method of thermal and hydraulic calculations, using the example of a shell-and-tube heat exchanger, taking into account the thermal conductivities of laminar and turbulent zones of coolant flows, based on the transfer of velocity and heat pulses in the radial direction of the pipeline cross-section. Based on the work of Reichardt and Ludwig [1, 3], and based on the fact that the turbulent Prandl number in the transitional zone of the LBL is unity, we used this to obtain new formulas (3), (4) and (5) calculation of the transitional viscosity and thermal conductivity in the transitional zones of LBLs, as well as to calculate the dimensionless number denoted by us $B l$ [11].

$$
\begin{aligned}
& \mu_{\text {trans }}=\frac{\sigma \cdot \cos \theta}{\sqrt{C_{p} \cdot 1^{0} K}} \\
& k_{\text {trans }}=\frac{\sigma \cdot \cos \theta \cdot C_{p}}{\sqrt{C_{p} \cdot 1^{0} K}} \\
& B l=\frac{\mu \cdot \sqrt{C_{p} \cdot 1^{0} K}}{\sigma \cdot \cos \theta}
\end{aligned}
$$

In the monograph Pirashvili et al., equations (6) and (7) are proposed for calculating turbulent viscosity in liquid and gas media, which appears in the middle of the pipeline at the socalled free turbulence $(\mathrm{a}=0,05-0,08)$ [9].

$$
\begin{aligned}
& \mu_{t u r b}=\mu \cdot a \sqrt{2 \cdot R e} \\
& k_{t u r b}=C_{p} \mu_{t u r b}
\end{aligned}
$$

\section{PROBLEM FORMULATION}

Some authors in the relevant papers point to the dominant influence of the thermal resistance of LBLs in the overall thermal resistance of the system (the heat transfer fluid - the boundary wall - the heat transfer fluid) in the heat exchange equipment. Proceeding from this, we set the following tasks in this work:

- is used the example of a shell-and-tube heat exchanger, calculated and selected by us in the work [9], to show the percentage of thermal resistances of individual zones of heat carriers flows and to determine their dominant contribution to the overall heat resistance of the heat exchanger;

- show how the values of the main turbulent thermophysical quantities change under turbulent motion in the volumes of liquid heat carriers in the shell-and-tube heat exchanger chosen by us;

- to propose a law for the distribution of the values of turbulent thermo-physical quantities in the volumes of the coolants flows, taking into account surface forces at the interface between of liquid heat carriers and the metal delimitating wall;

- proceeding from the proposed law, to calculate the values of thermo-physical quantities in the volumes of coolants flows by the example of a shell-and-tube heat exchanger, selected and calculated by us in the work [9];

- to offer the basic criteria for choosing the optimal energy efficient heat transfer medium for heat exchange equipment.

\section{RESULTS}

\subsection{The values of the thermal resistances of the various zones in the flows of the coolants of the shell-and-tube heat exchanger}

In the work [9], we calculated the corresponding shell-andtube heat exchanger for the classical method, using the criterion equations, Nusselt numbers and a new method, using formulas $(2,3,4,5,6,7,8)$. The calculation error was only $0.05 \%$ [9]. The heat exchanger chosen and calculated by us in the work [9] has such technical characteristics (Figure 1).

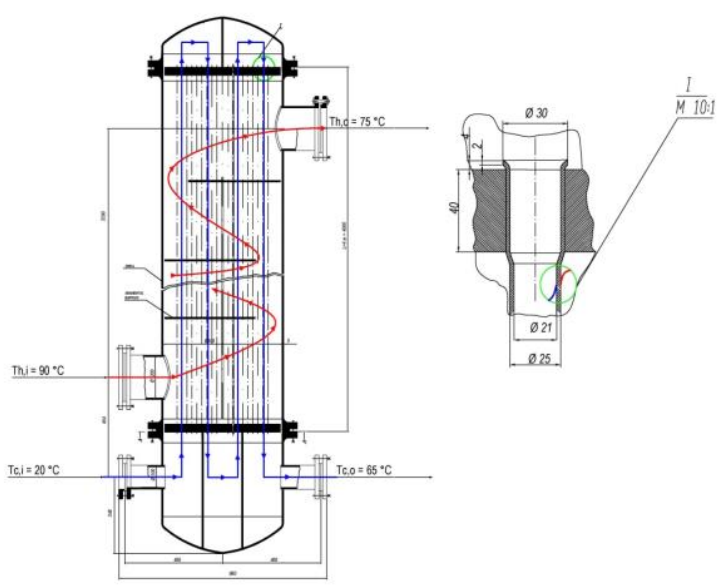

Figure 1. The scheme of shell-and-tube heat exchanger (number of passes $-\mathrm{z}=4$; number of pipes $-\mathrm{n}=206$;)

The exchanger has parameters: With the heat surface area $A$ $=97 \mathrm{~m}^{2}, D=0.6 \mathrm{~m}, z=4, \mathrm{n} / \mathrm{z}=51.5 ; n=206, L=6 \mathrm{~m}$. The area $A_{c}=4.5 \cdot 10^{-2} \mathrm{~m}^{2}$ (the cross-sectional area space between the tubes of the heat exchanger; Table 2.3 [11]). Inner diameter of pipes $-d_{i n}=21.10^{-3} \mathrm{~m}$. Outside diameter of the pipes $-d_{\text {out }}$ $=25 \cdot 10^{-3} \mathrm{~m}$. Cold milk is circulated in the pipes and hot water is circulated between pipes.

Using formulas $(2,3,4,5,6,7,8)$, in [9], using the formula 
(8), we calculated the total heat transfer coefficient of the chosen heat exchanger, having previously calculated the thermal resistances of all zones of coolants flows [9].

$$
\begin{aligned}
U_{\delta}= & \left(\frac{r_{h}-\delta_{h}}{k_{\text {turb.h }}}+\frac{\delta_{h}}{k_{\text {trans.h } h}}+\frac{\delta_{w}}{k_{w}}+\frac{\delta_{c}}{k_{\text {trans.c. }}}+\frac{r_{c}-\delta_{c}}{k_{\text {turb.c }}}+R_{\text {poll }}\right)^{-1}= \\
& \left(\begin{array}{l}
\frac{124.962 \cdot 10^{-4}}{43.02}+\frac{3.751 \cdot 10^{-6}}{3.387}+\frac{2 \cdot 10^{-3}}{17.5}+\frac{3.678 \cdot 10^{-5}}{2,09} \\
+\frac{104.632 \cdot 10^{-4}}{58.69}+\frac{2}{3000}
\end{array}\right)^{-1}=788.7 \mathrm{~W} \cdot \mathrm{m}^{-2} \cdot \mathrm{K}^{-1}
\end{aligned}
$$

In the formula (8) we introduced the numerical values of the thermal resistances of all these zones (Figure 2).

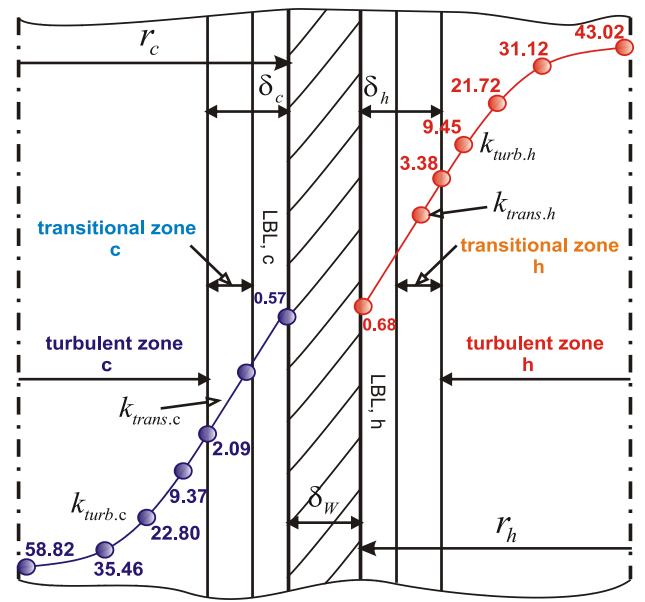

Figure 2. The scheme for contacting cold milk with hot water through a metal wall with the values of turbulent thermal conductivities in heat carriers streams

Table 1. Percentage of thermal resistances of the corresponding zones of heat carriers for water and milk, respectively (Figure 2)

\begin{tabular}{|c|c|c|}
\hline Parameters & Formula & Values \\
\hline $\begin{array}{c}\text { Thermal resistance of the turbulent } \\
\text { zone of hot water: }\end{array}$ & $\frac{r_{h}-\delta_{h}}{k_{\text {turb.h }}}$ & $22.9 \%$ \\
\hline $\begin{array}{c}\text { Thermal resistance of the LBL } \\
\text { zone of hot water: }\end{array}$ & $\frac{\delta_{h}}{k_{\text {trans.h }}}$ & $0.087 \%$ \\
\hline $\begin{array}{c}\text { Thermal resistance of the metal } \\
\text { boundary wall: }\end{array}$ & $\frac{\delta_{w}}{k_{w}}$ & $9.0 \%$ \\
\hline $\begin{array}{c}\text { Thermal resistance of the LBL } \\
\text { zone of cold milk: }\end{array}$ & $\frac{\delta_{c}}{k_{\text {trans.c }}}$ & $1.387 \%$ \\
\hline $\begin{array}{c}\text { Thermal resistance of the turbulent } \\
\text { zone of cold milk: }\end{array}$ & $\frac{r_{c}-\delta_{c}}{k_{\text {turb.c }}}$ & $14.06 \%$ \\
\hline $\begin{array}{c}\text { Thermal resistance of } \\
\text { contamination on both sides of the } \\
\text { metal wall: }\end{array}$ & $R_{\text {poll }}$ & $52.57 \%$ \\
\hline
\end{tabular}

From this calculation it follows that the thermal resistance of the turbulent zones of cold milk and hot water is almost $37 \%$ of the total system resistance. Add to this $52.57 \%$ of the thermal resistance of pollution, it is almost $90 \%$ of the thermal resistance. In addition, almost $9 \%$ of the thermal resistance falls on the metal separation wall, and only about $1.5 \%$ is the thermal resistance of the LBL.

Table 2. Specific thermal resistivity of the corresponding zones of heat carriers for water and milk, respectively (Figure 2)

\begin{tabular}{|c|c|c|}
\hline Parameters & Formula & Values, $\frac{m^{0} K}{W}$ \\
\hline $\begin{array}{c}\text { Specific thermal resistivity } \\
\text { of the turbulent zone of hot } \\
\text { water }\end{array}$ & $\frac{1}{k_{\text {turb.h }}}$ & $23.24 .10^{-3}$ \\
\hline $\begin{array}{c}\text { Specific thermal resistivity } \\
\text { of the LBL zone of hot } \\
\text { water }\end{array}$ & $\frac{1}{k_{\text {trans.h }}}$ & $295.253 .10^{-3}$ \\
\hline $\begin{array}{c}\text { Specific thermal resistivity } \\
\text { of the metal boundary wall }\end{array}$ & $\frac{1}{k_{w}}$ & $0.571 .10^{-4}$ \\
\hline $\begin{array}{c}\text { Specific thermal resistivity } \\
\text { of the LBL zone of cold } \\
\text { milk }\end{array}$ & $\frac{1}{k_{\text {trans.c }}}$ & $748.47 .10^{-3}$ \\
\hline $\begin{array}{c}\text { Specific thermal resistivity } \\
\text { of the turbulent zone of cold } \\
\text { milk }\end{array}$ & $\frac{1}{k_{\text {turb.c }}}$ & $17.04 .10^{-3}$ \\
\hline
\end{tabular}

As can be seen from the above analysis, the resistance of turbulent zones makes a significant contribution to the overall resistance of the shell-and-tube heat exchanger and is $23 \%$ and $14 \%$ for the pipes and between pipes, respectively. The specific resistance of LBLs reaches the highest values (Table 2 ), however, the total thermal resistance of these zones is small due to the fact that their average thickness is very small and amounts for cold milk $(c): \delta_{c}=3.678 \cdot 10^{-5} \mathrm{~m}$ and for hot water $(h): \delta_{h}=3.751 \cdot 10^{-6} \mathrm{~m} \mathrm{[9]}$.

\subsection{The dominant factors affecting the turbulent thermal conductivity of the turbulent zone of the coolant flow}

Today, the most difficult problems of heat and mass transfer, in particular in the theory of plasma, are solved with the help of the method of dimensional analysis [12]. We use this method in our research.

Let us consider the functional dependence of the turbulent heat conductivity of the coolant flow on a number of factors that, in our opinion, are dominant (9):

$$
\begin{aligned}
& k_{\text {turb. }}=f\left(\mu_{\text {turb. }}, V, \sigma, C_{P},(r-\Delta),\left({ }^{0} K\right)\right) \\
& k_{\text {turb. }}=B\left(\mu_{\text {turb. }}^{X} \cdot V^{Y} \cdot \sigma^{Z} \cdot C_{P}{ }^{M} \cdot(r-\Delta)^{E}\left({ }^{0} K\right)^{s}\right) ;
\end{aligned}
$$

We perform a dimensional analysis of the functional dependence (9). All the thermo-physical quantities are represented in terms of the main dimensions of quantities mass, linear size, time and temperature $\left[\mathrm{kg}, \mathrm{m}, \mathrm{s},{ }^{0} \mathrm{~K}\right]$.

$$
\begin{aligned}
& k_{\text {turb. }}-\left[W \cdot m^{-1} \cdot K^{-1}=N \cdot m \cdot s^{-1} \cdot m^{-1} \cdot K^{-1}=k g \cdot m \cdot s^{-3} \cdot K^{-1}\right] ; \\
& \mu_{\text {turb. }}-\left[\text { Pa.s }=N \cdot s \cdot m^{-2}=k g \cdot m^{-1} \cdot s^{-1}\right] ; V-\left[m^{3} \cdot s^{-1}\right] ; \\
& \sigma-\left[N \cdot m^{-1}=k g \cdot m \cdot s^{-2} \cdot m^{-1}=k g \cdot s^{-2}\right] ; \\
& C_{P}-\left[N \cdot m \cdot k g \cdot{ }^{-1} K^{-1}=k g \cdot m^{2} s^{-2} \cdot k g^{-1} \cdot K^{-1}=m^{2} \cdot s^{-2} \cdot K^{-1}\right] ; \\
& (r-\Delta)-[m] ;{ }^{0} K-\left[K^{1}\right]
\end{aligned}
$$


We represent the exponential equation in the form of an equation of dimensions.

$$
\begin{aligned}
& {\left[k g \cdot m \cdot s^{-3} \cdot K^{-1}\right]=B\left[k g \cdot m^{-1} \cdot s^{-1}\right]^{X}\left[m^{3} \cdot s^{-1}\right]^{Y}\left[k g \cdot s^{-2}\right]^{Z}} \\
& {\left[m^{2} \cdot s^{-2} \cdot K^{-1}\right]^{M}[m]^{E}\left[K^{1}\right]^{S}}
\end{aligned}
$$

We present such a system of equations for the exponents, taking into account the dimensional equation.

$$
\begin{gathered}
X+Z=1 ; \quad-X+3 Y+2 M+E=1 ; \quad-X-Y-2 Z-2 M=-3 ; \\
Z=1-X ; M=0.5 X+0.5 ; \quad S=M-1 ; S=0.5 X-0.5 ; E=0 ; Y=0 ; \\
k_{\text {turb. }}=B\left(\mu_{\text {turb. }}^{X} \cdot V \cdot \sigma^{1-X} \cdot C_{P}^{(0.5+0.5 X)} \cdot K^{(-0.5+0.5 X)}(r-\Delta)\right): \sigma \cdot \sqrt{C_{P} / 1^{0} K} ;
\end{gathered}
$$

Grouping all the terms and unknown powers in one unknown power of $X$, we obtain the equation (10):

$$
\frac{k_{\text {turb. }}}{\sigma \cdot \sqrt{C_{p} \cdot 1^{0} K}}=B\left(\frac{\mu_{\text {turb. }} \sqrt{C_{p} \cdot 1^{0} K}}{\sigma}\right)^{X} ;
$$

$\sigma \cdot \sqrt{C_{p} \cdot 1^{0} K}=k_{\text {trans. }}-$ transitional thermal conductivity in the transitional zone LBL (Figure 2) [9].

The formula (10) is rewritten in the form (11), taking into account the hydrophilicity of the surface of the metal wall.

$$
\frac{k_{\text {turb. }}}{\sigma \cos \theta \sqrt{C_{p} \cdot 1^{0} K}}=B\left(\frac{\mu_{\text {turb. }} \sqrt{C_{p} \cdot 1^{0} K}}{\sigma \cos \theta}\right)^{X} ;
$$

The left-hand side of relation (11) is the ratio of turbulent and transitional heat conductivity. The right-hand side of equation (11) is a dimensionless number-an analogue of the number of $B l$, derived from our work [9]. Therefore, we will call its turbulent number $B l_{\text {turb. }}$, where the turbulent viscosity appears. It will be used for calculations not in the LBL region, as the number $B l$, but in the zone of free turbulence, that is, outside the LBL area. Proceeding from equation (11), we can use Eqns. $(12,13)$ to find the maximum turbulent heat conductivity in the central part of the heat carrier flow.

$$
\begin{aligned}
& k_{\text {turb. }}=B\left(\frac{\mu_{\text {turb. }} \cdot \sqrt{C_{p} \cdot 1^{0} K}}{\sigma \cos \theta}\right)^{X} \sigma \cos \theta \sqrt{C_{p} \cdot 1^{0} K} ; \\
& B l_{\text {turb. }}=\frac{k_{\text {turb. }}}{k_{\text {trans. }}}=\frac{\mu_{\text {turb }}}{\mu_{\text {trans }}}=B\left(\frac{\mu_{\text {turb. }} \cdot \sqrt{C_{p} \cdot 1^{0} K}}{\sigma \cos \theta}\right)^{X} ;
\end{aligned}
$$

$B l_{\text {turb. }}$ number shows the degree of turbulence of the coolant in the center of the flow (in the zone of free turbulence) with respect to turbulence in the transitional layer of the LBL. The degree of turbulence of the turbulent part of the flow will depend on the magnitude of the turbulent viscosity, which in turn depends on the flow rate of the refrigerant, ie, on its flow rate, as well as on a number of other factors. In formula (12), the unknown value of the turbulent viscosity of the coolant flow remains. Therefore, a further step in our research will be to find the law of distribution of turbulent viscosity in the volume of the coolant.

\subsection{The main factors affecting the turbulent viscosity in the} volumes of coolants flows in the zones of free turbulences

Let us consider the functional dependence of the turbulent viscosity of the coolant flow, which enters into formulas (12) and (13) on a number of factors that, in our opinion, are dominant. Represent this equation in the form of a function (14):

$$
\begin{aligned}
& \mu_{\text {turb. }}=f\left(V, \sigma, \mathrm{C}_{p},(r-\Delta)\right) ; \\
& \mu_{\text {turb. }}=B\left(V^{Y} \cdot \sigma^{Z} \cdot C_{p}{ }^{M} \cdot(r-\Delta)^{E}\right) ;
\end{aligned}
$$

We shall carry out a dimensional analysis of such a functional dependence. All the thermo-physical quantities are represented in terms of the main dimensions of quantities mass, linear size, time and temperature $\left[\mathrm{kg}, \mathrm{m}, \mathrm{s},{ }^{0} \mathrm{~K}\right]$. Dimensions are similar to the above.

We represent the exponential equation in the form of an equation of dimensions.

$$
\left[k g \cdot m^{-1} \cdot s^{-1}\right]=B\left[m^{3} \cdot s^{-1}\right]^{Y}\left[k g \cdot s^{-2}\right]^{Z}\left[m^{2} \cdot s^{-2} \cdot K^{-1}\right]^{M}[m]^{E}\left[K^{1}\right]^{S} ;
$$

We represent the system of equations for the exponents with allowance for the dimensional equation.

$$
\begin{aligned}
& Z=1 ; \quad 3 Y+2 M+E=-1 ; \quad-Y-2 Z-2 M=-1 ; \\
& 2 M=-1-Y ; \quad E=-2 Y ; \quad 0=-M+S ; \quad S=M ; \\
& \mu_{\text {turb. }}=B\left(V^{Y} \cdot \sigma^{1} \cdot C_{p}^{(-0.5-0.5 Y)}(r-\Delta)^{(-2 Y)} \cdot K^{(-0.5-0.5 Y)}\right): \frac{\sigma}{\sqrt{C_{p} \cdot 1^{0} K}} ;
\end{aligned}
$$

Having grouped all terms and unknown powers to one unknown power of $Y$, we obtain equation (15), taking into account the hydrophilicity of the wetting surface. For convenience, the exponent of the power of $Y$ is automatically changed to $X$, since we are accustomed to such a general unknown value of $X$.

$$
\frac{\mu_{\text {turb. }} \sqrt{C_{p} \cdot 1^{0} K}}{\sigma \cos \theta}=B\left(\frac{V}{(r-\Delta)^{2} \sqrt{C_{p} \cdot 1^{0} K}}\right)^{X}
$$

$\frac{\sigma \cos \theta}{\sqrt{c_{p} \cdot 1^{0} K}}=\mu_{\text {trans. }}-$ coefficient of transitional viscosity in the transitional zone LBL (Figure 2) (see work [9]).

It is easy to see that in the brackets on the right-hand side of equation (15) we have the ratio of the average velocity of the flow (the ratio of the volume flow rate of the refrigerant to the cross-sectional area of the pipes) to the value, reflecting the average velocity of the thermal motion of the coolant molecules (the value $\sqrt{C_{p} \cdot 1^{0} K}$ ). Since the total refrigerant flow extends to all pipes, in formula (15) we need to enter the value $(n / z)$. Then this flow rate will correspond to the flow rate in one heat exchanger tube. In addition, in formula (15) it is necessary to introduce the number $\mathrm{Pi}$, since it enters the crosssectional area of one tube and is not fixed by the method of dimensional analysis. The value of the average velocity of thermal movement of the refrigerant molecules is much higher than the average linear velocity of the refrigerant. In the right side of equation (15) the numerator must be replaced by a denominator. Then the exponent of degree $X$ gets a minus sign. 
Taking into account the hydrophilicity of the surface, equation (15) takes the form (16). This equation is valid for the tubular space of the heat exchanger. For a space with a shell, equation (16) takes the form (17). In equation (17), the number Pi is not introduced, but the conditional radius is calculated from the cross-sectional area of the $A_{c}=4.5 .10^{-2} \mathrm{~m}^{2}$ pass, taking into account the total number of the pipes $(n=206)$. The value of $\Delta-$ is the step of the radius of the coolant flow in the pipes or the conditional radius in the annular space, with which we move away from the center of the coolant flow to the wall.

$$
\begin{aligned}
& B l_{\text {turb.c }}=\frac{1}{B l_{c}}\left(\frac{\pi\left(r_{c}-\Delta\right)^{2} \frac{n}{z} \sqrt{C_{p . c} \cdot 1^{0} K}}{V_{c}}\right)^{-X_{c}} \frac{\mu_{c} \sqrt{C_{p . c} \cdot 1^{0} K}}{\sigma_{c} \cos \theta} \\
& B l_{\text {turb.h }}=\frac{1}{B l_{h}}\left(\frac{\pi\left(r_{h}-\Delta\right)^{2} n \sqrt{C_{p . h} \cdot 1^{0} K}}{V_{h}}\right)^{-X_{h}} \frac{\mu_{h} \sqrt{C_{p . h} \cdot 1^{0} K}}{\sigma_{h} \cos \theta}
\end{aligned}
$$

The left side of Eq. (16) is the ratio of turbulent viscosity to transitional viscosity, that is, the ratio of maximal turbulent viscosity of the coolant in the middle of the stream to the minimal in the transitional zone of LBL. This relation is a dimensionless turbulent number of $B l_{\text {turb. }}$ (Formula 13).
The right-hand side is the ratio of the quantity reflecting the average rate of thermal motion of the molecules, i.e., the maximal velocity at the molecular level, to the vectors of the average linear velocities of the motion of the carriers flow the minimal velocities.

According to our preliminary calculations based on the choice of the heat exchanger in [11], the exponent in equation (16) is $P r_{t u r b . c}=0.733$. The exponent of $X$ in equation (17), i.e, for the annular space $-P r_{\text {turb.h }}=0.573$, which agrees very well and correlates with work [3, pp. 707].

From equations $(16,17)$, we plotted the dependences of velocities, turbulent viscosities, thermal conductivities, as well as the turbulent numbers $B l_{\text {turb. }}$. in the tube and inter tubular space of the heat exchanger (Figure 1), i.e. showed the distributions of these thermo-physical characteristics in the volumes of the flows of heat carriers. The volumes flow rates of liquids (coolants) $V_{c}$ and $V_{h}$ and all other parameters included in the formulas $(16,17)$ we used from work [9] for the shell-and-tube heat exchanger (Figure 1) and two model liquids (milk and water). The presented graphs are undoubtedly analogues of bell-shaped curves, which obey the laws of physics surface phenomena. The graphs are the numerical values of turbulent viscosities, thermal conductivities and turbulent numbers $B l_{\text {turb. }}$. depending on the distance from the axis of the center of the pipe or the conditional center of the space between the pipes of the shelland-tube heat exchanger (Figure 3).
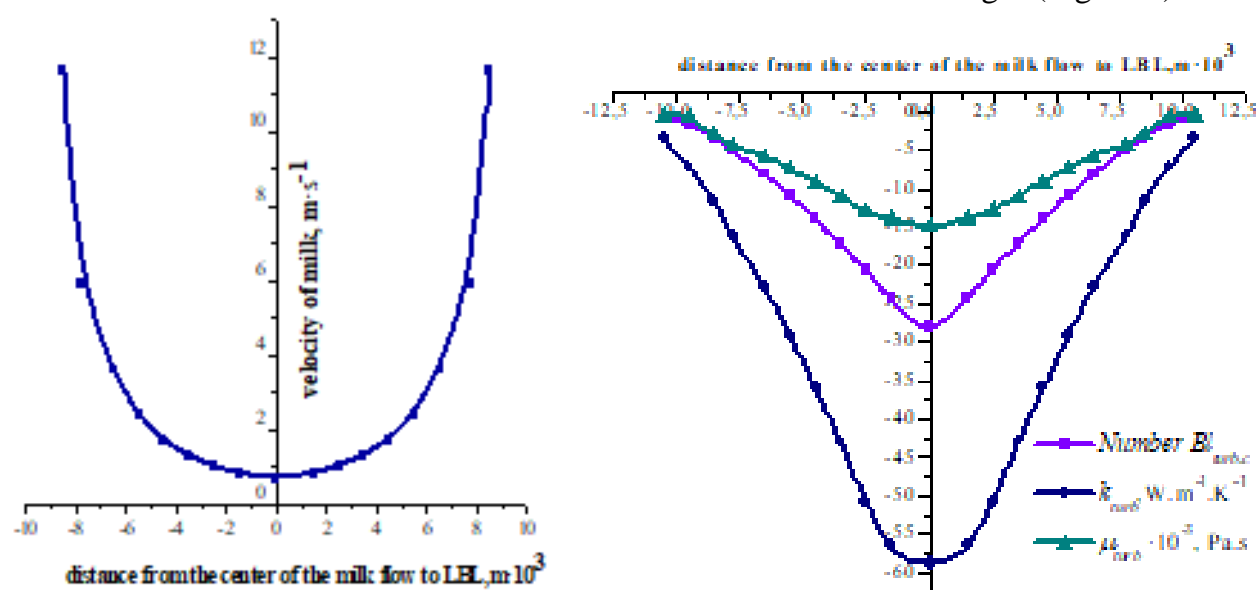

(a)
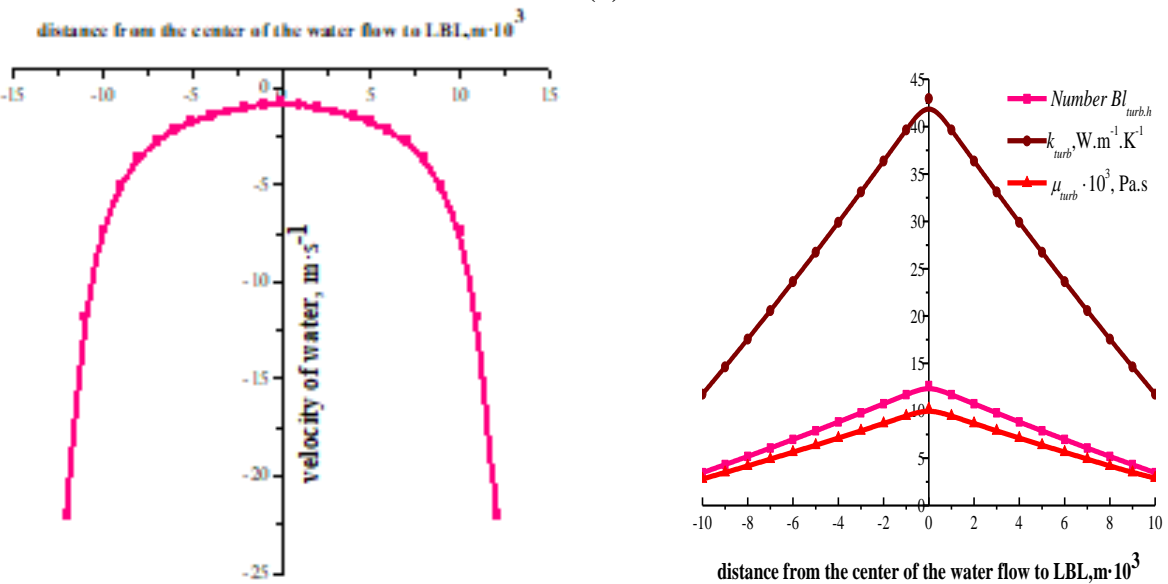

(b)

Figure 3. Distribution of linear velocities $v_{c}$, as well as the turbulent numbers $B l_{t u r b}$, turbulent viscosities $\mu_{\text {turb. and thermal }}$ conductivities $k_{t u r b}$, in the volumes of the flows of model liquids-coolants: (a) - cold milk, (b) - hot water 
The charts built for such parameters of the milk and water at medium temperatures of heat carriers:

$$
\begin{aligned}
& C_{\text {p.c. }}=3.91410^{3} \mathrm{~J} \cdot \mathrm{kg}^{-1} \cdot \mathrm{K}^{-1} \quad C_{p . h .}=4.19810^{3} \mathrm{~J} \cdot \mathrm{kg}^{-1} \cdot \mathrm{K}^{-1} \\
& \sigma_{c}=47.7510^{-3} \mathrm{~N} \cdot \mathrm{m}^{-1} ; \quad ; \quad \sigma_{h}=62.2510^{-3} \mathrm{~N} \cdot \mathrm{m}^{-1} ; \\
& V_{c}=\frac{\dot{m}_{c}}{\rho_{c}}=11.764 \cdot 10^{-3} \mathrm{~m}^{3} \cdot \mathrm{s}^{-1} \quad V_{h}=\frac{\dot{m}_{h}}{\rho_{h}}=34.6 \cdot 10^{-3} \mathrm{~m}^{3} \cdot \mathrm{s}^{-1} ; \\
& r_{c}=10.5 \cdot 10^{-3} \mathrm{~m} ; \quad r_{h}=10.0 \cdot 10^{-3} \mathrm{~m} ; \\
& X_{c}=0.733 ; \quad X_{h}=0.573 ; \\
& \cos \theta=0.7-0.84 ; \quad \Delta=1.0 \cdot 10^{-3} \mathrm{~m} ; n=206 ; \quad \mathrm{z}=4 \text {; }
\end{aligned}
$$

3.4 Correlation of the proposed character of distributions of thermo-physical quantities in coolants flows with the studies of other independent authors

The nature of the distribution of thermal-physical quantities in the volume of coolants flows is similar to the experimental curves obtained by Schlichting H., Reichard H., Ludwig H., Fontmann E. et al. Which are presented in a monograph by $\mathrm{H}$. Shlihting [2].

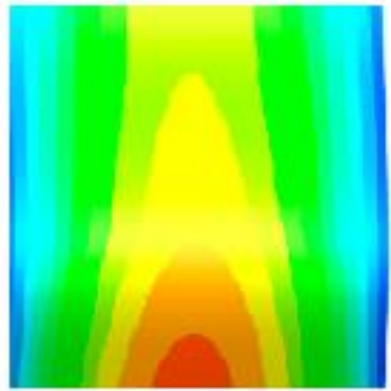

Temperature (K)

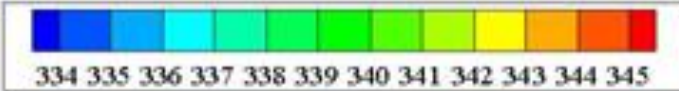

Figure 4. The distribution of the temperature field in the channel of the plate heat exchanger [13, Figure 10b]

The graphs and the nature of the changes in the turbulent viscosities, thermal conductivities, and turbulent number $B l_{\text {turb }}$ in the streams of coolants of milk and water almost completely coincide with the nature of the change in the temperature-field front, which moves in the channel of the plate heat exchanger (Figure 4). These thermo-grams were obtained in [13, Figure 10 b] by the authors Yuan Xue, Jihua Ge et al.

The results of our work correlate well with [14], where the authors Iype, E. et al. (2012) as a result of modeling the molecular dynamics of the water flow between two platinum plates indicate the formation of a surface monolayer, where thermal jumps and large thermal resistances arise at the boundary of platinum with water. This surface monolayer of water molecules differ in structure from structure to volume and is associated with the action of surface forces (Figure 5).

It can be seen from the Figure 5, that the maximum specific thermal resistances occur at the boundary between silver and water. Based on our research, the maximum specific thermal resistances are also noted at the boundary of the metal wall of the heat exchanger and LBL of the heat transfer fluids (Table 2 and Figure 2).

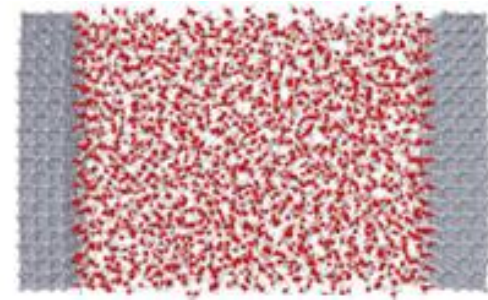

(a)

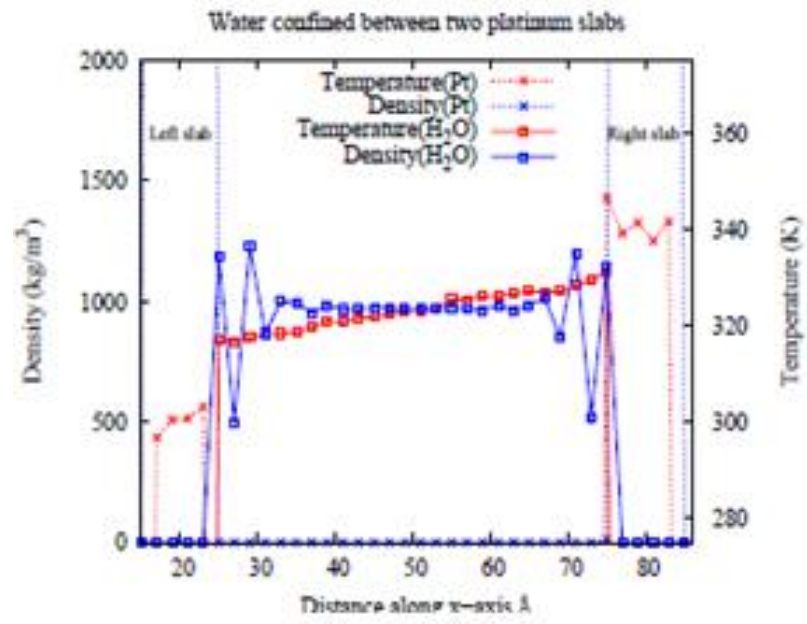

(b)

Figure 5. Heat transfer between two platinumslabs (resembling a hannel) whih condensed layer of water: (a) Platinum slabs are atta hed with a thermostat at $300 \mathrm{~K}$ on the left and at $340 \mathrm{~K}$ on the right; (b) The distribution of temperature and density a ross the hannel. [14, Figure 4]

Formulas $(12,13$ and 16,17) completely correlate with the conclusions of the work of Maurizio Quadrio Pierre Ricco [15], where it is shown that the laminar part of the flow completely controls the turbulent part of it. The turbulent number $B l_{t u r b}$, deduced by us, is responsible for the turbulent part of the flow, the multiplier $\sigma \cos \theta \sqrt{C_{p} \cdot 1^{0} K}$ represents the transitional thermal conductivity in the LBL transitional zone and is responsible for the laminar and transitional part inside the LBL.

Equations $(16,17)$ is an undoubted analogue of equation (1), since the right part of it is the ratio of velocities, and the left is the ratio of the maximum and minimum turbulent viscosity or the maximum and minimum turbulent thermal conductivity responsible for the transfer of thermal energy, and hence the temperature in the volume of the flows of the coolants. The exponent of $X$ is the turbulent Prandl number $P r_{t u r b}$, the ratio the pulse and heat coefficients in the middle of the pipeline.

Recall that the pioneer in the study of turbulent viscosity in fluids flows is Joseph Boussinesq [16].

It should be noted that the issues of turbulent viscosity and thermal conductivity in aerodynamics of air were dealt with by Movchan V. T. et al. in the corresponding works [17, 18]. However, these questions are considered from the point of view of the mechanics of gases and liquids with the use of complex differential equations, which as Schlichting $\mathrm{H}$., points out in their works, is difficult to apply for engineering calculations. Our work correlates with the above. We are considering the process of distribution of velocity and heat pulses in the case of free turbulence of liquids from the point of view of the physics of surface phenomena. The calculation of turbulent viscosities and thermal conductivities in the volume of heat carriers flows using, for example, Eqns. (12, $13,16,17)$ it seems to us rather simple. 
It should also be emphasized that our theoretical studies correlate well with the very vivid experiments performed in the work [19] of Parag Chaware and C.M. Sewatkar, which show the thermos-grams of the cross section of liquid flows in the pipeline at different stages of the swirler in the tube and at different Reynolds numbers (Figure 6).

The thermo-grams clearly show the LBLs near the pipe walls and near the metal surface of the swirler, whose temperature is much lower than at the center of the pipe. At higher values of Reynolds numbers, the average thickness of the LBL on thermo-grams is significantly reduced.

The positive effect of the swirler, in our opinion, is manifested in the fact that it increases the impulses of the flow rate of the refrigerant in the radial direction, allowing more intensive transfer of heat to the wall of the heat exchange surface.

Indisputable is the fact that in the volume of the liquid heat carrier there is a change in the thermal conductivity of the flow, which is distributed according to the bell-shaped law. This depends on the magnitude of the turbulent viscosity, which in turn depends on the refrigerant flow rate and the thermalphysical characteristics included in the number $B l_{\text {turb. }}$. The change in the thermal conductivity in the volume of the turbulent fluid flow is indicated in other papers.

Our studies correlate well with the work [20], where three types of heat-conducting tubes are compared (bare, floral and hydrophilic). They are arranged in accordance with the increase in the heat transfer properties of solid surfaces and the increase in their hydrophilicity. The effect of SAS is manifested by the stronger, the more hydrophobic the surface of the tube.

In the present work, we calculated the turbulent thermal conductivities in the central parts of the coolants flows using the formulas (16 and 17). As a result, we obtained similar values of turbulent thermal conductivities, which we presented in (Figure 3) respectively blue (for milk) and red (for water) as according to calculations in our work, which we calculated from the known formulas $(5,6)$. This fact once again speaks of the correlation of our research with many other works of independent authors and confirms the reliability of the data obtained, contributing to the further study of the problems of heat and mass transfer in turbulent flows of liquid carriers. It should also be noted that the values of turbulent thermal conductivities in the central part of the flow of liquid heat carriers $\left(58.82 \mathrm{~W} \cdot \mathrm{m}^{-1} \cdot \mathrm{K}^{-1}\right.$, for milk and $43.02 \mathrm{~W} \cdot \mathrm{m}^{-1} \cdot \mathrm{K}^{-1}$ for water) are 2-3 times higher than the thermal conductivities, for example, stainless $\left(17.5 \mathrm{~W} \cdot \mathrm{m}^{-1} \cdot \mathrm{K}^{-1}\right)$, and almost close to thermal conductivities, for example, carbones steels and casts irons $\left(45 \mathrm{~W} \cdot \mathrm{m}^{-1} \cdot \mathrm{K}^{-1}\right)$. Somewhat unusual is the fact that in classical calculations of heat exchange equipment in the empirical numerical equations of Nusselt we use the values of thermal conductivities of stationary liquids, for example, for milk $\left(0.57 \mathrm{~W} \cdot \mathrm{m}^{-1} \cdot \mathrm{K}^{-1}\right)$ and for water $\left(0.68 \mathrm{~W} \cdot \mathrm{m}^{-1} \cdot \mathrm{K}^{-1}\right)$, which are hundreds of times less than the thermal conductivities of these liquids in areas of high turbulence. This fact suggests that the calculation of heat and mass transfer equipment according to the classical Nusselt equations is advantageous when we are dealing with well-known analogues, both equipment and heat transfer media, which transmit a quantity of heat. When, for example, nanopowders are used in coolants to improve their heat transfer properties, the application of classical methods becomes problematic. It is necessary to re-do the experiments for the appropriate coolants and heat exchangers, since the classical equations become unsuitable. In addition, such empirical equations, as a rule, are very cumbersome.

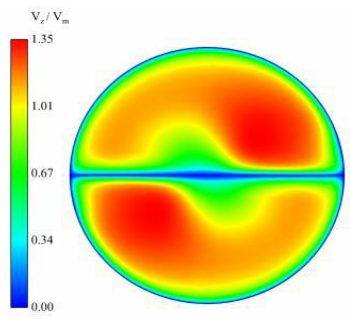

(a)

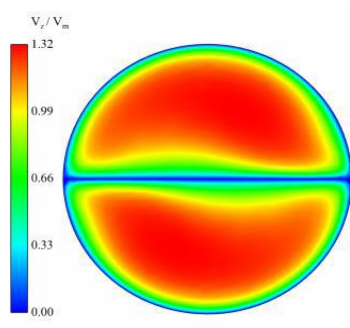

(c)

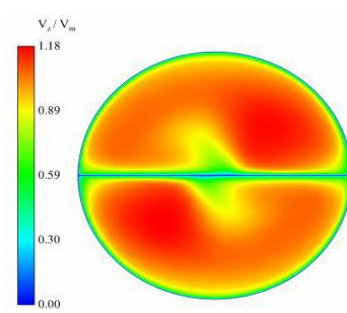

(b)

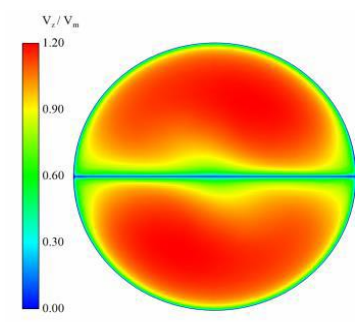

(d)
Figure 6. Axial velocity contours for the fully developed flow at (a) $\mathrm{Y}=4$ and $\operatorname{Re}=4000$ (b) $\mathrm{Y}=4$ and $\mathrm{Re}=30000$ (c) $\mathrm{Y}=10$ and $\mathrm{Re}=4000$ (d) $\mathrm{Y}=10$ and $\operatorname{Re}=30000$ [19, Figure 6]

It should also be noted that with the turbulent number $B l_{t u r b}$, it is possible to select a suitable energy-efficient refrigerant in heat exchange equipment, having previously calculated the value of the turbulent viscosity in the middle of the refrigerant flow by the formulas $(16,17)$, or according to the well-known formula (5). In this case, we calculated the turbulence numbers $B l_{\text {turb }}$ for a number of refrigerants, which are often used in heatexchange equipment. The results are shown in Table 3 .

Values are convenient for calculation, having a known value $\mathrm{Bl}_{\mathrm{turb}\left(\mathrm{H}_{2} \mathrm{O}\right)}$, for example, for water. Since formula (5) includes the viscosity and the Reynolds number under the root, formulas $(16,17)$ include turbulent viscosity and the specific heat of the refrigerant under the root in the numerator, and the surface tension coefficient in the denominator, we obtain the ratio (18):

$$
\frac{B l_{\text {turb }(X)}}{B l_{\text {turb }\left(H_{2} O\right)}}=\frac{\sigma_{\left(H_{2} O\right)} \cdot \cos \theta_{\left(H_{2} O\right)} \sqrt{\mu_{(X)} \cdot C_{P(X)}}}{\sigma_{(X)} \cdot \cos \theta_{(X)} \cdot \sqrt{\mu_{\left(H_{2} O\right)} \cdot C_{P\left(H_{2} O\right)}}}
$$

Values of thermal physical values for ethylene-, propylene-, dipropylene glycols, are taken from the source [21].

An obstacle to the use of propylene- and di propylene glycols in shell-and-tube heat exchangers can be a significant decrease in Reynolds numbers due to the high dynamic viscosity coefficients. In this case, the refrigerant flow can move to the area of laminar flow regimes. Therefore, Table 3 presents the Reynolds numbers for the respective refrigerants at a given refrigerant flow rate and its flow rate, which correspond to the example of the shell-and-tube heat exchanger selected and calculated by us in the work [9]. We assume that the refrigerant moves in the space of the tubes of this heat exchanger. 
Table 3. Value of the turbulent number $B l_{\text {turb }}$ (energy efficiency indicator) and Reynolds number for model liquids of water and milk and for liquid coolants at a temperature of $40{ }^{\circ} \mathrm{C}$ and $5{ }^{\circ} \mathrm{C}$ temperature

\begin{tabular}{|c|c|c|c|c|}
\hline \multirow[t]{2}{*}{$\begin{array}{c}\text { Liquid - } \\
\text { phase coolant }\end{array}$} & \multicolumn{2}{|c|}{$\begin{array}{c}\begin{array}{c}\text { Turbulent } \\
\text { number } B l_{\text {turb. }} \\
\text { (maximal) }\end{array} \\
B l_{t u r b .}= \\
\frac{\mu_{t u r b .} \sqrt{C_{p \cdot} \cdot 1^{0} K}}{\sigma \cos \theta}\end{array}$} & \multicolumn{2}{|c|}{$\begin{array}{c}\begin{array}{c}\text { Reynolds } \\
\text { number }\end{array} \\
\operatorname{Re}=\frac{v d \rho}{\mu}= \\
=\frac{4 m}{\pi d_{i n} n / z \cdot \mu}\end{array}$} \\
\hline & $40^{\circ} \mathrm{C}$ & $5{ }^{0} \mathrm{C}$ & $40^{\circ} \mathrm{C}$ & $5^{\circ} \mathrm{C}$ \\
\hline Water & 12.48 & 17.96 & 21514 & 9423 \\
\hline Milk & 21.58 & 29.92 & 12850 & 4383 \\
\hline Ethylene glycol $20 \%$ & 22.20 & 32.02 & 13857 & 5235 \\
\hline Propylene glycol $25 \%$ & 25.65 & 34.95 & 9954 & 2192 \\
\hline Dipropylene glycol $25 \%$ & 51.47 & 72.48 & 11726 & 2221 \\
\hline Propylene glycol $38 \%$ & 36.12 & 59.27 & 6254 & 996 \\
\hline Dipropylene glycol $38 \%$ & 40.40 & 65.16 & 7004 & 1340 \\
\hline Propylene glycol $47 \%$ & 42.66 & 73.95 & 5483 & 649 \\
\hline Dipropylene glycol $47 \%$ & 49.22 & 77.76 & 6327 & 667 \\
\hline
\end{tabular}

As is known, the critical value of the Reynolds number for the tubular space of a shell-and-tube heat exchanger is $\operatorname{Re}_{\mathrm{c}} \approx$ 2320 , and for the space between the pipes $-\operatorname{Re}_{\mathrm{c}} \approx 1000$. Table 3 shows that most aqueous solutions of propylene- and di propylene glycols are not very suitable for use at low temperatures in shell-and-tube heat exchangers, since their values Reynolds numbers at $5{ }^{\circ} \mathrm{C}$ correspond to the laminar flow regime, where the overall heat transfer coefficients will have low values, and their use at such temperatures is inefficient. When cooling food and convenience foods, plate heat exchangers should be used, in which the corrugated plates turbulize the refrigerant flows, and the critical value of Reynolds numbers corresponds to $\operatorname{Re}_{\mathrm{c}} \approx 50$. An exception may be shell-and-tube heat exchangers with special turbulizing inserts, the application of which was studied in the work [22]. These inserts significantly reduce the critical value of the Reynolds number, but the use of such inserts is also problematic due to the increased hydraulic resistance and difficult access to cleaning the pipes and spiral metal swirlers. The distribution of turbulent viscosities and thermal conductivities in the channels of the corrugated plates in plate heat exchangers will be the subject of our further research.

This work will have its continuation, since in the work [23] presented the possibility of creating super hydrophilic or super hydrophobic metal surfaces using high-frequency laser processing, which can significantly increase heat transfer coefficients. These surfaces are created by analogy with the surfaces of various plants, which have undergone a long evolutionary development [24]. The only obstacle for such a large-scale technology, as the authors themselves say, is its relative high cost.

In the aforementioned works $[5,6,7]$, we also proposed the idea of modifying steel surfaces with metal-clad damping lubricants for as well as by electrolytic hydrogenation.

In this paper, we propose to modify not the metal surface, but refrigerant adjacent to the metal wall in the direction of its hydrophilization by searching for cheap, non-toxic, natural SAS for the corresponding liquid food product, for example, for milk. An appropriate natural natural SAS of low concentration can be selected for other liquid products or semifinished products, such as juices, broths, cream and others, which will significantly increase the energy efficiency of food, pharmaceutical, chemical and other technologies. These works will be the subject of our further research.

\section{CONCLUSIONS}

1. The distribution of thermal resistances and specific heat resistances is analyzed on the example of a shell-tube heat exchanger, which we have chosen and calculated in the work [9].

2. It is shown that the thermal resistance of turbulent zones of heat carriers is about $37 \%$ of the total thermal resistance of the system in the heat exchanger.

3. Specific thermal resistances of heat carriers are maximum in the LBL zones, since they have a minimum thermal conductivity, but the total thermal resistances are minimal, since they have a very small average thickness (Figure 2).

4. By the method of dimension analysis we theoretically deduced a new dimensionless number $B l_{\text {turb }}$, which is applicable for calculation of turbulent thermal-physical quantities in heat carrier flows in zones of free turbulence.

5. The formula for calculating the turbulent thermal conductivity and viscosity and the law of their distribution in the volume of heat carrier flows are obtained by the method of analyzing the sizes of the basic physical quantities.

6. It is shown that the law of distribution of turbulent thermo-physical quantities in the volume of coolant flows described by equations $(16,17)$ is analogous to equation (1), that is, the bell-shaped distribution of Reichardt, Ludwig and others, and also almost completely coincides with the thermograms presented in the work [13].

7. The main difference between the proposed law for the distribution of values of turbulent thermal-physical quantities in the volume of coolant flows is that our ratio contains the coefficients of surface tension and the cosines of the wetting angles and takes into account the physical interaction of the surfaces of the individual phases and liquid mediums.

8. The degree of turbulence of the coolant flows shows the turbulent number $B l_{\text {turb }}$ which is the ratio of turbulent viscosities or turbulent thermal conductivities in mediums flows in zones of high turbulence to transitional viscosities or transitional thermal conductivities in LBL (Egulation 13).

9. A complete analysis in the volume of the heat carrier flows was made using milk and water as examples in the shelltube heat exchanger with their turbulent viscosity and thermal conductivity values, as well as turbulent number $B l_{t u r b}$, values (Figure 2).

10. The proposed distribution law does not contradict the basic theories of turbulence proposed by Prandtl L., Reynolds O., Taylor G., Karman Th. et al.

11. With the help of the turbulent number $B l_{\text {turb }}$ deduced by us, it is possible to choose the most energy efficient liquid heat carriers for specific heat exchange processes.

\section{REFERENCES}

[1] Reichardt H. (1944). Impuls - und Wärmeaustausch bei freier Turbulenz. ZAMM 24: 268-272. http://dx.doi.org/10.1002/zamm.19440240515

[2] Schlichting H. (1979). Boundary - Layer Theory. pp. 706-707, 752-753, 741, 747, 749, 754. 
[3] Ludwieg H. (1956). Bestimmung des Verhältnisses der Austauschkoeffizient für Wärme und Impuls bei turbulenten Grenzschichten, ZFW 4, pp. $73-81$.

[4] Rogacki G. (1989) The general form of representation of wall region of a turbulent boundar layer. Wärme - und Stoffübertragung 24(6): 375-379. https://doi.org/10.1007/BF01592785

[5] Pokhmurskii VI, Sirak YM, Bilonoga YL. (1984). Influence of the surface energy and of the energy of the bond of the contacting metals on the fretting fatigue life of the joints of machine parts. Soviet Materials Science 20(4): 358-360. https://doi.org/10.1007/BF01199367

[6] Bilonoga YL, Pokhmurs'kii VI. (1991). A connection between the fretting-fatigue endurance of steels and the surface energy of the abradant metal. Soviet Materials Science 26(6):

629-633 https://doi.org/10.1007/BF00723647

[7] Pokhmurskii VI, Bilonoga YL, Sirak YM, German NV. (1986). Some principles of the development of a frettingresistant lubricant. Soviet Materials Science 21(6): 593595. https://doi.org/10.1007/BF00722252

[8] Wang XZ. (2017). Experiment study on the corrosion mechanism of mortar anchor solid. Chemical

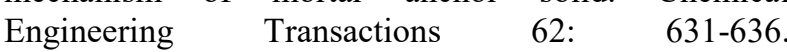
https://doi.org/10.3303/CET1762106

[9] Bilonoga Y, Maksysko O. (2017). Modeling the interaction of coolant flows at the liquid-solid boundary with allowance for the laminar boundary layer. International Journal of Heat and Technology 35(3): 678682. http://dx.doi.org/ 10.18280/ijht.350329

[10] Pirashvili SA, Polyaev VM, Sergeev MN. (2000). Vortex effect. experiment, theory, technical solutions, Moscow. UNPU, Energomash, pp. 170-179.

[11] Dytnerskij YI. (1991). Basic processes and devices of chemical technology (Manual of engineering). Moskwa, Chemistry, pp. 14-70.

[12] Bahman Zohuri. (2015). Dimensional analysis and selfsimilarity methods for engineers and scientists. Book, p. 511. http://dx.doi.org/10.1007/978-3-319-13476-5

[13] Xue Y, Ge ZH, Du XZ, Yang LJ. (2018). On the heat transfer enhancement of plate fin heat exchanger. Energies 11(6): 1398. https://doi.org/10.3390/en11061398

[14] Iype E, Arlemark EJ, Nedea SV, Rindt CCM, Zondag HA. (2012). Molecular dynamics simulation of heat transfer through a water layer between two platinum slabs. Journal of Physics: Conference Series 395: 012111. http://dx.doi.org/10.1088/1742-6596/395/1/012111

[15] Quadrio M, Ricco P. (2011). The laminar generalized Stokes layer and turbulent drag reduction. Journal of Fluid Mechanics 667: 135-157. http://dx.doi.org/10.1017/S0022112010004398

[16] Darrigol O. (2017). Joseph Boussinesq's legacy in fluid mechanics. Comptes Rendus Mécanique 345(7): $427-$ 445. http://dx.doi.org/ 10.1016/j.crme.2017.05.008

[17] Movchan VT, Shkvar EA. (1996). Modelling of dynamics and heat transfer processes in turbulent nearwall shear flows. Proc. of the 2nd European Thermal Sciences and 14th UIT National Heat Transfer Conference, 29-31 May, Rome, Italy. - Edizioni ETS, Pisa. pp. 535-540.

[18] Movchan VT, Shkvar EA. (2010). Different-level mathematical models of the coefficient of turbulent viscosity. Applied Hydromechanics 12(1): 55-67. http://dspace.nbuv.gov.ua/handle/123456789/87725

[19] Chaware P, Sewatkar CM. (2018). Effects of tangential and radial velocity on fluid flow and heat transfer for flow through a pipe with twisted tape insert-laminar flow. Sādhanā, Springer India 43(9): 150. https://doi.org/10.1007/s12046-018-0893-z

[20] Yoon JI, Kim ES, Choi KH, Seol WS. (2002) Heat transfer enhancement with a surfactant on horizontal bundle tubes of an absorber. International Journal of Heat and Mass Transfer 45(4): 735-741. https://doi.org/10.1016/S0017-9310(01)00202-2

[21] Dymlent HE, Kazansky KS, Miroshnikov AM. (1976). Glycols and other derivatives of oxides of ethylene and propylene, Moscow, Chemistry, 38-44, 172-194.

[22] Panahi D, Zamzamian K. (2017). Heat transfer enhancement of shell-and-coiled tube heat exchander utilizing helical wiere turbulator. Applied Thermal Engineering 115: 607-615. https://doi.org/10.1016/j.applthermaleng.2016.12.128

[23] Vorobyev AY, Guo C. (2015). Multifunctional surfaces produced by femtosecond laser pulses. Journal of Applied Physics. Published Online: 20 January 2015.117, 033103. http://dx.doi.org/10.1063/1.4905616

[24] Koch K, Bhushan B, Barthlott W. (2009). Multifunctional surface structures of plants: An inspiration for biomimetics. Progress in Materials Science 54(2): 137-178. https://doi.org/10.1016/j.pmatsci.2008.07.003

\section{NOMENCLATURE}

A heat transfer area, $\mathrm{m}^{2}$

$A_{c} \quad$ cross-sectional area, $\mathrm{m}^{2}$

$A_{\tau} \quad$ exchange coefficients for momentum, $\mathrm{kg} \cdot \mathrm{m}^{-1} \cdot \mathrm{s}^{-1}$

$A_{q} \quad$ exchange coefficients for heat, $\mathrm{kg} \cdot \mathrm{m}^{-1} \cdot \mathrm{s}^{-1}$

a experimental coefficient

$B \quad$ unknown constant

$B l \quad$ dimensionless number

$B l_{\text {turb. }} \quad$ turbulent dimensionless number

$C_{p} \quad$ specific heat capacity, $\mathrm{J} . \mathrm{kg}^{-1} \cdot \mathrm{K}^{-1}$

$C_{p . c} \quad$ specific heat capacity of milk, $\mathrm{J}_{\mathrm{kg}} \mathrm{kg}^{-1} \cdot \mathrm{K}^{-1}$

$C_{p . h} \quad$ specific heat capacity of water, $\mathrm{J}_{\mathrm{kg}} \mathrm{kg}^{-1} \cdot \mathrm{K}^{-1}$

$E \quad$ unknown constant

$\cos \theta$ cosine of the contact angle, dimensionless

$d \quad$ diameter of the pipeline, $\mathrm{m}$

$d_{\text {in }} \quad$ inner diameter of pipes, $\mathrm{m}$

$d_{\text {out }} \quad$ outside diameter of pipes, $\mathrm{m}$

$D \quad$ shell diameter, $\mathrm{m}$

Kturb coefficient of turbulence

$k \quad$ thermal conductivity, W. $\mathrm{m}^{-1} \cdot \mathrm{K}^{-1}$

$k_{\text {trans }}$ transitional thermal conductivity in the LBL transitional zone, $\mathrm{W} \cdot \mathrm{m}^{-1} \cdot \mathrm{K}^{-1}$;

$k_{\text {turb.c }}$ coefficient of average turbulent thermal conductivity of cold milk, W. $\mathrm{m}^{-1} \cdot \mathrm{K}^{-1}$;

$k_{\text {turb.h }}$ coefficient of average turbulent thermal conductivity of hot water, W. $\mathrm{m}^{-1} \cdot \mathrm{K}^{-1}$

$L \quad$ length of the pipeline, $\mathrm{m}$

$M \quad$ unknown constant

$\dot{m} \quad$ mass flow rate, $\mathrm{kg} . \mathrm{s}^{-1}$

$n \quad$ number of the tubes

$\mathrm{Pr} \quad$ Prandtl number

$P r_{\text {turb }} \quad$ Prandtl number turbulent 
$\Delta P \quad$ pressure drop along the pipe or unit, $\mathrm{Pa}$

$r \quad$ pipeline radius, $\mathrm{m}$

$r_{c} \quad$ radius of the "live section" of the cold carrier stream, $\mathrm{m}$

$r_{h} \quad$ radius of the "live section" of the hot carrier stream, $\mathrm{m}$

$R_{\text {poll }} \quad$ thermal resistance of pollutants

Re Reynolds number

$T$ temperature, ${ }^{\circ} \mathrm{C}$

$T_{\min } \quad$ minimal temperature, ${ }^{\circ} \mathrm{C}$

$T_{\max } \quad$ maximal temperature, ${ }^{\circ} \mathrm{C}$

$U_{\delta} \quad$ the overall heat transfer coefficient at the average thickness of the LBL, W. $\mathrm{m}^{-2} . \mathrm{K}^{-1}$

$V \quad$ volume flow rate of liquid (coolant), $\mathrm{m}^{3} \cdot \mathrm{s}^{-1}$

$V_{c} \quad$ volume flow rate of milk, $\mathrm{m}^{3} . \mathrm{s}^{-1}$

$V_{h} \quad$ volume flow rate of water, $\mathrm{m}^{3} . \mathrm{s}^{-1}$

$v_{c} \quad$ velocity of the milk, $\mathrm{m} \cdot \mathrm{s}^{-1}$

$v_{h} \quad$ velocity of the water, $\mathrm{m} \cdot \mathrm{s}^{-1}$

$v_{\min } \quad$ minimal velocity, $\mathrm{m} . \mathrm{s}^{-1}$

$v_{\max } \quad$ maximal velocity, $\mathrm{m} . \mathrm{s}^{-1}$

$X \quad$ unknown degree

$X_{c} \quad$ unknown degree for milk

$X_{h} \quad$ unknown degree for water

$Y \quad$ unknown degree

$z \quad$ number of the passes

Z unknown degree

\section{Greek symbols}

$\delta \quad$ average thickness of the LBL, $\mathrm{m}$

$\delta_{w} \quad$ thickness of the tube wall, $\mathrm{m}$

$\mu \quad$ dynamic viscosity coefficient, $\mathrm{kg} \cdot \mathrm{m}^{-1} \mathrm{~s}^{-1}$

$\mu_{\text {trans. }} \quad$ coefficient of transitional viscosity of coolant, $\mathrm{kg} \cdot \mathrm{m}^{-1} \mathrm{~s}^{-1}$

$\mu_{\text {turb. }} \quad$ coefficient of turbulent viscosity of coolant, $\mathrm{kg} \cdot \mathrm{m}^{-1} \mathrm{~s}^{-1}$

$\rho \quad$ fluid density, $\mathrm{kg} \cdot \mathrm{m}^{-3}$

$\sigma \quad$ surface tension coefficient of coolant, N.m ${ }^{-1}$

$\Delta \quad$ the step of the radius of the coolant flow in the pipes or in the annular space, $\mathrm{m}$

\section{Subscripts}

$\begin{array}{ll}c & \text { cold } \\ c r & \text { critical } \\ \text { in } & \text { input } \\ h & \text { hot } \\ \text { LBL } & \text { laminar boundary layer } \\ \text { min } & \text { minimal } \\ \text { max } & \text { maximal } \\ \text { out } & \text { output } \\ \text { SAS } & \text { surfactants } \\ \text { trans } & \text { transitional } \\ \text { turb } & \text { t urbulent } \\ \text { w } & \text { wall }\end{array}$

